DOSSIÊ TEMÁTICO: Política de Educação Superior

do] https://doi.org/10.22481/praxisedu.v16i41.7244

\title{
EXPANSÃO E FINANCIAMENTO DA PÓS-GRADUAÇÃO E DESIGUALDADE REGIONAL NO BRASIL (2002-2018)
}

EXPANSION AND FINANCING OF GRADUATE AND REGIONAL INEQUALITY IN

BRAZIL (2002-2018)

\author{
EXPANSIÓN Y FINANCIAMENTO DE LA POS-GRADUACIÓN Y DESIGUALDAD \\ REGIONAL EN BRASIL (2002-2018)
}

André Rodrigues Guimarães

Universidade Federal do Amapá - Brasil

Cristiane de Sousa Brito

Universidade Federal do Amapá - Brasil

José Almir Brito dos Santos

Universidade Federal do Amapá - Brasil

\begin{abstract}
Resumo: O presente estudo tem como objetivo analisar a expansão e o financiamento da Pós-Graduação Stricto Sensu, no período 2002-2018, considerando o contexto de desigualdade regional brasileira. A pesquisa, com abordagem quali-quantitativa, tem como base empírica os dados estatísticos do Sistema de Informações Georreferenciadas da CAPES (GEOCAPES) e da Execução Orçamentária da União. Os resultados apontam expressivo movimento de expansão da Pós-Graduação no país, com índices mais acentuados nas regiões Norte e Nordeste, mas também revelam ainda haver elevada concentração no eixo sul-sudeste. Em relação ao financiamento, destaca-se a elevada redução orçamentária da CAPES, a partir de 2014, com fortes implicações na manutenção dos Programas, particularmente no que diz respeito aos auxílios financeiros a pesquisadores e estudantes. Em síntese, conclui-se que sem o necessário financiamento público serão aprofundadas as disparidades regionais na Pós-Graduação brasileira.
\end{abstract}

Palavras-chave: Pós-Graduação stricto sensu; Desigualdade regional; Financiamento.

Abstract: This research has the aim to analyze the expansion and funding of the Stricto Sensu Graduate, during 2002 and 2018, considering the context of Brazilian regional inequality. The research with qualitative and quantitative approach has like empirical basis the static data of the information system georeferenced of CAPES (GEOCAPES) and of Union Budget Execution. The results indicate expressive expansion movement of the Graduate Course in the country with more accentuated indexes in North and Northeast regions, but also show still there high concentration in the south-southeast axis. About financing stands out the high budget reduction of CAPES from 2014 with substantial implications in maintenance of programs, specially about for financial aid for researchers and students. In summary, it 
is concluded that without the necessary public funding the regional disparities will be deepen in Brazilian Graduate.

Keywords: Stricto Sensu Graduate; Regional inequality; Funding.

Resumen: El presente estudio tiene como objetivo analizar la expansión y fnanciamineto de la Posgraduación Stricto Sensu, en el periodo 2002-2018, considerando el contexto de desigualdad regional brasileña. La investigación, tiene un enfoque cuantitativo y cualitativo, como base empírica de los datos estadísticos del Sistema de Informaciones Georreferenciadas de la CAPES (GEOCAPES) y de la Ejecución Presupuestario de la Unión. Los resultados apuntan un movimiento expresivo de expansión de la Pos-graduación en el país, con índices más acentuados en las regiones Norte y Noreste, mas también revelan haber alcanzado una elevada concentración en el eje Sur-Sureste. En relación al financiamiento se destaca una elevada reducción presupestaria de la CAPES, a partir de 2014, con fuertes inplicaciones en la manutención de los Programas, particularmente en relación a los auxilios financieros de invetigadores y estudiantes. En síntesis, se concluye que sin el financiamiento público serán profundizadas las diferencias regionales en la Pos-graduación brasileña.

Palabras clave: Pos-graduación stricto sensu; Desigualdad Regional; Financiamiento.

\section{Introdução}

Este estudo tem como tema a expansão e o financiamento da Pós-Graduação Stricto Sensu no Brasil ${ }^{1}$. Analisamos especificamente a evolução histórica no período entre 2002-2018, no número de Programas e Cursos. Também consideramos a dotação orçamentária do Ministério da Educação (MEC) e da Coordenação de Aperfeiçoamento de Pessoal de Nível Superior (CAPES), com destaque para o orçamento destinado como Auxílio Financeiro para pesquisadores e estudantes. A análise sobre a temática considera o contexto da desigualdade regional que marca o país a qual também se manifesta no âmbito da educação superior (SGUISSARDI, 2008; BRITO; GUIMARÃES, 2017).

$\mathrm{Na}$ atual conjuntura, com o explícito ataque do governo Jair Bolsonaro à educação superior, particularmente à Pós-Graduação, tal estudo apresenta-se como relevante. A compreensão do processo de expansão e do necessário financiamento dos cursos de mestrado e doutorado no país nos permitirá prognosticar prováveis problemas que serão ocasionados se não houver adequado financiamento da educação superior pública, especialmente no âmbito da Pós-Graduação em sua distribuição regional.

\footnotetext{
${ }^{1}$ Estudo decorrente de Projeto de Pesquisa, sobre expansão e financiamento da educação superior no Brasil, financiada pelo CNPq (Chamada Universal 01/2016).
} 
A abordagem metodológica utilizada neste estudo considera a necessidade de superação da falsa polarização entre quantidade e qualidade na pesquisa social (GAMBOA, 1995). Buscamos uma abordagem metodológica "que possibilite mais elementos para descortinar as múltiplas facetas do fenômeno investigado, atendendo os anseios da pesquisa. Caracteriza-se como um movimento científico, que se opõe a histórica dicotomia quantitativaqualitativa." (SOUZA \& KERBAUY, 2017, p. 40). Entendemos a realidade como dinâmica e complexa, a qual exige também dos pesquisadores postura ativa na coleta e análise dos dados - o que envolve posições teórico-epistemológicas e elimina a noção de neutralidade. Desse modo, mesmo quando se trabalha com dados estatísticos, como é o caso deste estudo, a análise vai além da simples leitura de dados, na tentativa de articulá-los ao contexto social, que envolve reflexões teóricas.

Embasados nessa perspectiva, para realização da pesquisa, utilizamos outros estudos que tratam da temática, e, principalmente, os dados estatísticos do Sistema de Informações Georreferenciadas da CAPES (GEOCAPES), bem como dados da Execução Orçamentária da União, este último disponibilizado pela Câmara dos Deputados Federais. Os dados financeiros foram atualizados a preço de janeiro de 2019, considerando o Índice de Preço ao Consumidor Amplo (IPCA) $)^{2}$.

Optamos por considerar especificamente a CAPES, por ser esse o principal órgão de fomento da Pós-Graduação no Brasil ${ }^{3}$. Esse órgão, desde sua origem, se configura como órgão dotado de capacidade de atuar no financiamento e na formulação das políticas que orientam a Pós-Graduação Stricto Sensu no país. Trata-se da principal instituição normatizadora, com função de controle, avaliação e financiamento desse nível formativo. Na atualidade, por seu papel central, conforme destaca Silva Júnior (2017), constitui-se em agência reguladora responsável pela efetivação da reforma universitária no âmbito da Pós-Graduação.

Por sua função reguladora e indutora, a CAPES também tem papel relevante na configuração da pesquisa e Pós-Graduação no contexto da desigualdade regional brasileira. Assim, pode atuar na perspectiva de reduzir ou ampliar as desigualdades característica da formação econômica e social do país, uma vez que essas disparidades são refletidas na expansão do nível superior de ensino, como aponta Sguissardi (2008, p. 29), “[...] é na educação superior que se pode verificar [...] o problema da relação da educação e diversidade regional, ou melhor, podem observar-se as maiores assimetrias regionais neste campo".

\footnotetext{
${ }^{2}$ Para atualização utilizamos sempre as médias anuais do IPCA.

${ }^{3}$ O Conselho Nacional de Desenvolvimento Científico e Tecnológico (CNPq) também desempenha papel importante nesse processo, particularmente com a concessão de bolsas e financiamento de pesquisadores.
} 
Além desta introdução e das considerações finais, este estudo está estruturado em três seções. Na primeira, refletimos sobre a formação econômica do Brasil, evidenciando a desigualdade regional como elemento estruturante desse processo. Em seguida, analisamos a expansão da Pós-Graduação brasileira com ênfase em sua distribuição regional. Na terceira seção, exploramos o financiamento da CAPES, particularmente para Auxílios Financeiros a pesquisadores e estudantes.

\section{Desigualdade regional na formação econômica brasileira}

Antes de analisarmos a expansão da Pós-Graduação brasileira, no período entre 2002 e 2018, com foco na sua distribuição regional, é fundamental fazermos algumas considerações sobre as desigualdades regionais que estão presentes em nossa formação histórica. Nesse sentido, é preciso considerarmos o fato da formação do Brasil ser marcada pela não superação de diversas desigualdades interrelacionadas que se manifestam na sociedade, dentre elas, as desigualdades regionais que podem ser notadas em alguns aspectos. Em meio a esses aspectos, destaca-se o desequilíbrio da distribuição de renda e do acesso à educação nos diferentes níveis de ensino. Esse é um problema histórico de debate insuficiente no campo da educação.

No Brasil, a distribuição de renda ocorre desproporcionalmente entre as regiões. Isso porque o transcurso do desenvolvimento econômico do país tendeu a privilegiar determinadas regiões em prejuízo de outras. Tal situação foi constituída historicamente e ainda representa a atual realidade da política econômica do país. Em decorrência disso, o eixo Sul-Sudeste concentra a maior parte da renda nacional - ressalta-se que ainda assim, em tais regiões, há também elevada desigualdade na distribuição de renda e condições de vida.

Quando o Brasil ainda era colônia de Portugal, o centro econômico estava localizado no Nordeste, isso mantinha os grupos elitistas nessa região e garantia notoriedade a ela. Foi na região Nordeste, mais especificamente nos estados de Pernambuco e Bahia, que a atividade açucareira atingiu o mais elevado grau de desenvolvimento, transformando essa região em um importante centro econômico do Brasil entre os séculos XVI e XVII. Prado Júnior (1961) enfatiza o sucesso da região que em mais de século e meio manteve uma produção que foi quase a única base da economia brasileira. No período, as elites da colônia se concentravam na parcela do território que sustentava a sua riqueza e lá permaneceram até o esgotamento da atividade produtiva. Isso possibilitou Portugal acumular riquezas com o comércio do açúcar e também iniciar o povoamento do país. 
Já em relação à região Norte, em que suas riquezas eram alvo para exploração, Fausto (1995) afirma que a colonização ocorreu muito lentamente, e a sua integração econômica ao mercado europeu foi precária até segunda metade do século XVIII. Segundo o autor, as tentativas de implantação de uma agricultura exportadora, baseada no algodão e açúcar, fracassaram. De modo geral, o que predominou por muito tempo nessa região foi o trabalho compulsório indígena na comercialização das drogas do sertão, atividade econômica que não garantiu o desenvolvimento regional. Após essas tentavas de exploração não bem-sucedidas, a região Norte ficou esquecida por Portugal.

Com as descobertas de minérios de ouro em Minas Gerais, Goiás e Mato Grosso, o Nordeste perde o foco dos interesses portugueses. Com o ouro descoberto nas regiões Sudeste e Centro-Oeste do país, e a crescente concorrência holandesa na produção do açúcar, o governo português concentra seus esforços na exploração desses minerais, que foram responsáveis pelo crescimento urbano e do comércio locais. Para além dessas regiões, a mineração se expandiu para quase todo o território nacional. No século XVIII, a atividade passou a ser a mais lucrativa da metrópole (FAUSTO, 1995). O movimento propiciou mudanças significativas como “[...] o deslocamento do eixo econômico da colônia, antes localizado nos grandes centros açucareiros do Nordeste (Pernambuco e Bahia). A própria capital da colônia “[...] transfere-se em 1763 da Bahia para o Rio de Janeiro.” (PRADO JÚNIOR, 1961, p. 65). Esse foi o início da marginalização social para a região Nordeste e sua entrada no cenário de exclusão social no país.

Entre os séculos XVIII e XIX, a implantação de uma nova cultura no Sudeste do país traz um novo momento para a economia brasileira, o cultivo do café. Esta atividade viabilizou a chegada de diversos imigrantes europeus a região, com o objetivo de trabalhar nas lavouras (FAUSTO, 1995). O café tornou-se o principal produto de exportação do país, exportando mais de $50 \%$ do produto para consumo mundial.

Como decorrência desse processo, já no século XX, a industrialização do país também ocorrerá de forma desigual entre as regiões, privilegiando umas e colocando outras a margem do desenvolvimento. Assim, conforme destaca Oliveira (2009, p. 15), o crescimento econômico do Brasil, "[...] do ponto de vista industrial, aconteceu de forma desordenada e concentrada geograficamente. O processo ocorreu, principalmente, nas regiões Sudeste e Sul, sobretudo no Estado de São Paulo, acarretando profundas desigualdades regionais no restante do país”.

O desenvolvimento brasileiro tem como prioridade o aspecto econômico em detrimento do social, isso por fazer parte de uma lógica de produção que tem interesse maior 
no acúmulo de riqueza para a manutenção do poder no domínio dos grupos empresariais e políticos. Furtado (1998) contribui com o debate afirmando que, em meio ao processo do desenvolvimento, os maiores problemas que o Brasil enfrenta se expressam na pobreza, na concentração de renda e nas desigualdades regionais. O curso do progresso econômico refletiu em um projeto de país desenvolvido, mas com crescentes problemas sociais.

O sistema econômico do Brasil revela um Estado que se retira de sua função em proporcionar condições adequadas para a melhoria de vida da população e que desconsidera o fato de que a política financeira de um país é capaz de superar a exclusão social vivenciada internamente por seus povos. Diferente do que se materializa na prática, "o crescimento econômico deve ser visto como um meio de aumentar o bem-estar da população e de reduzir o grau de miséria que pune parte dela [...].” (FURTADO, 1998, p. 80). No entanto, o modelo de desenvolvimento limitado ao enfoque econômico permanece ativo no Brasil.

Quando se analisa o processo de desenvolvimento desigual do Brasil, um ponto importante a ser considerado é o estado de dependência que se encontra em relação a países de grande potencial econômico. A atual conjuntura que reflete o passado colonial não se trata de questão recente, uma vez que “[...] a situação de dependência e subordinação orgânica e funcional da economia brasileira, com relação ao conjunto internacional de que participa, é um fato que se prende às raízes de formação do país.” (PRADO JÚNIOR, 1961, p. 275). A relação com o capital internacional se fortalece e os transtornos sociais internos são esquecidos pelo Estado, e, consequentemente, acentuados.

A economia nacional centra suas bases na exportação de matérias-primas e importação de produtos industrializados. Ainda que tenha uma produção interna, o consumo do que vem do estrangeiro torna-se expressivo em razão de os produtos brasileiros serem considerados inferiores em qualidade quando comparados aos estrangeiros que entram no país, o que ocasiona queda no consumo do que é local e supervalorização do que vem de fora. Essa política não beneficia toda a população, assim como não permite que todos tenham acesso aos importados, só acessa quem tem poder aquisitivo para tal, o que certamente contribui para as injustiças sociais. Para Prado Júnior (1961, p. 315),

Uma economia como a nossa, que se apoia essencialmente na produção de matérias-primas e gêneros alimentares de baixo valor com cuja exportação contamos exclusivamente para pagarmos as importações necessárias à manutenção da população do país e de suas atividades econômicas, bem como para o pagamento, sob forma de juros, de dividendos e amortização, do capital estrangeiro aqui aplicado, uma tal economia é incapaz de sustentar no país um nível elevado de vida; e o desequilíbrio, com todas suas tremendas consequências que estamos no presente momento sentindo tão duramente, se 
torna fatal logo que se sai dos padrões mais ínfimos de existência. E a continuarmos no sistema tradicional da economia brasileira, que ainda é substancialmente o de hoje, as perspectivas do futuro não são melhores.

Em vista dessa situação, o Brasil permanece com uma política claramente de dependência que é evidenciada em acordos, parcerias internacionais e legislações orientadas nesse sentido. As políticas públicas aparecem envolvidas pelo discurso de atendimento as demandas da população e de justiça social, quando, na essência, o que existe é um arcabouço político voltado não para a dita justiça, mas com a função de controle social de uma elite sobre a população, e, ainda, um controle internacional sobre essa elite. Prado Júnior (1961, p. 283) continua sua análise ao afirmar que a vida econômica brasileira "[...] não é função de fatores internos, de interesses e necessidades da população que nele habita; mas de contingências da luta de monopólios e grupos financeiros internacionais concorrentes".

No plano mundial ocorre a classificação dos países entre "desenvolvidos" e "subdesenvolvidos", de acordo com seu potencial econômico. Nos países ditos subdesenvolvidos ou em desenvolvimento, como o Brasil, existe um impulso ao crescimento econômico, político e social para determinadas regiões e as demais são colocadas à margem. Tal dinâmica, própria do capitalismo, não permite que todos alcancem o desenvolvimento; assim, o equilíbrio do capital incide no desequilíbrio entre os Estados e em seu interior.

Essa análise não pode desconsiderar que o modelo econômico vigente é capitalista. Desse modo, temos no Brasil “[...] um tipo de Estado criado pela burguesia para reproduzir na sua estrutura e funcionamento as características das relações sociais e econômicas que constituem o modo de produção capitalista." (BIANCHETTI, 1997, p. 78). Levando em conta que o capitalismo é sustentado pela exploração de uns em favorecimento de outros, nesse modelo, as desigualdades sociais das mais diversas são inerentes ao sistema.

Tais elementos fazem com que o histórico processo econômico desigual se arraste até a contemporaneidade. Considerando o indicador Renda familiar per capita, o mais utilizado pelos pesquisadores da economia para medir a distribuição de renda do país, constata-se esse cenário. De acordo com um relatório publicado pela Oxfam Brasil ${ }^{4}$ intitulado "País Estagnado: um retrato das desigualdades brasileiras", divulgado em 2018, o Brasil é modelo de país desigual em muitos pontos e suas diferenças entre ricos e pobres só aumentam.

\footnotetext{
${ }^{4}$ A Oxfam Brasil é uma organização sem fins lucrativos e independente, com escritório localizado em São Paulo. Faz parte de uma confederação global que afirma ter como objetivo combater a pobreza, as desigualdades e as injustiças em todo o mundo. Disponível em: https://www.oxfam.org.br/quem-somos/oxfam-brasil. Acesso em: 28 de mai. 2019.
} 
Dentre outras questões, o documento expõe dados sobre a renda de ricos e pobres de estados de regiões mais ricas e mais pobres, criando, assim, um comparativo entre rendas das regiões. Segundo o Relatório:

O rendimento médio dos 50\% mais pobres no Distrito Federal (R\$1.059,00, o maior entre as UFs) é mais de três vezes superior ao rendimento dos $50 \%$ mais pobres do Piauí (R \$ 341,00, a menor entre as UFs). Da mesma forma, a renda média dos $10 \%$ mais ricos em São Paulo (R\$ 12.816,00) é quase três vezes a renda média dos $10 \%$ mais ricos no Maranhão ( $\mathrm{R} \$ 4.669,00)$ (OXFAM, 2018, p. 24).

O relatório permite a comparação das rendas e a confirmação das diferenças alarmantes que permanecem estagnadas, não apresentando redução. Essa realidade afeta diretamente o campo da educação, posto que a distribuição de renda está relacionada com o acesso e permanência na escola e/ou universidade. Isso pelo fato das pessoas com baixo poder aquisitivo serem, também, as que pouco ascendem nos níveis de ensino. Tal como veremos, essa situação também se manifesta no âmbito da Pós-Graduação.

\section{Expansão da Pós-Graduação nas regiões brasileiras (2002-2018)}

A Pós-Graduação também reflete o quadro de imposições mundiais que o país se sujeita para se adequar à dinâmica global capitalista. A lógica do mercado encontra-se presente na indução do conhecimento produzido pelas universidades públicas. Esse conhecimento é orientado na direção de fornecer produtos imediatamente rentáveis para capital. A lógica consiste na geração de lucro no comércio global, ou seja, na criação de "conhecimento matériaprima que, de pronto, possa ser transformado em produtos, processos e serviços e alcance no mercado mundial, tal como se pode ver consolidado nas instituições americanas." (SILVA JÚNIOR, 2017, p. 250). Este consolidado desempenho da Pós-Graduação no Brasil contribui para uma expansão regionalmente concentrada nas regiões industrializadas, mais ricas economicamente.

Em estudo específico sobre a expansão da Educação Superior e diversidade regional no Brasil, Sguissardi (2008) apresenta como resultados: desiguais rendimentos da população de cada região; acentuadas disparidades entre as regiões quando verificados os números de concluintes da educação superior; um processo de privatização da educação superior e dos cursos de Pós-Graduação; destaque positivo para a expansão da Pós-Graduação no Sudeste e baixa expansão no Norte do país. O autor atribui ênfase na realidade dual que vivencia o país: 
de um lado regiões favorecidas que concentram renda e altos indicadores de cursos de graduação e Pós-Graduação, de outro lado regiões que sofrem exclusões sociais (Norte e Nordeste), com pobreza e baixos índices educacionais.

Diante da falta de vontade política, "são pouco promissoras, no curto ou médio prazo, as perspectivas de respeito às diversidades regionais ou de diminuição das imensas disparidades e assimetrias na educação superior em nosso país" (SGUISSARDI, 2008, p. 45). O enfrentamento a essa situação exige a ampliação da intervenção estatal, com políticas públicas sociais que almejem a superação da exclusão social que assola o país. Logo, faz-se necessário alterar a histórica função exercida pelos sucessivos governos.

Em síntese, trata-se de reverter a tendência das políticas em curso, as quais aprofundam a privatização da educação superior. No contexto neoliberal, o poder público reduz sua atuação direta "na promoção/oferta da educação superior gratuita e universal para desenvolver formas regulatórias que acabam por transferir a oferta da educação em grande escala à iniciativa privada" (ANDRADE; SIMÕES, 2020, p. 403).

Essas reflexões, fundamentais para a análise realizada no presente artigo, nos auxiliam na compreensão do processo de expansão da Pós-Graduação do Brasil. Essa investigação será realizada considerando sempre o cenário nacional, com destaque para sua efetivação regional. Serão considerados os Programas e cursos.

A Tabela 1 apresenta os dados referentes ao quantitativo de Programas, os quais foram agrupados conforme os cursos que os compõem - Mestrado Acadêmico (MA); Mestrado Profissional (MP); Mestrado e Doutorado Acadêmicos (MA/DA); e Doutorado Acadêmico (DA).

A tendência geral aponta para significativo movimento de expansão em todas as modalidades analisadas. O total de Programas cresceu 155,7\%, os Programas somente com Doutorado registraram crescimento com índice semelhante, 156,3\%. Os Programas de Mestrados Profissionais foram os que mais se expandiram: alcançaram a incrível marca de 1.352,9\%. A menor expansão foi de Programas de Mestrado Acadêmico, que ainda assim atingiram $94.1 \%$ - isso também se explica pelo fato de muitos dos Programas passarem também a contemplar cursos de Doutorado, resultando na ampliação do número de Programas Acadêmicos com Mestrado e Doutorado (os quais cresceram em 133,8\%). 
Tabela 1: Número de Programas de Pós-Graduação no Brasil (2002-2017)

\begin{tabular}{cccccccccc} 
Ano & Total & \multicolumn{2}{c}{ MA } & \multicolumn{4}{c}{ MP } & \multicolumn{3}{c}{ MA/DA } & \multicolumn{2}{c}{ DA } \\
& & Num. & \% & Num. & \% & Num. & \% & Num. & \% \\
$\mathbf{2 0 0 2}$ & 1683 & $665^{*}$ & 39,5 & 51 & 3,0 & $935^{* *}$ & 55,6 & 32 & 1,9 \\
$\mathbf{2 0 0 4}$ & 1930 & 759 & 39,3 & 116 & 6,0 & $1.023^{* * *}$ & 53,0 & 32 & 1,7 \\
$\mathbf{2 0 0 6}$ & 2265 & 923 & 40,8 & 157 & 6,9 & 1.146 & 50,6 & 39 & 1,7 \\
$\mathbf{2 0 0 8}$ & 2567 & 1.029 & 40,1 & 218 & 8,5 & 1.284 & 50,0 & 36 & 1,4 \\
$\mathbf{2 0 1 0}$ & 2840 & 1.091 & 38,4 & 247 & 8,7 & 1.453 & 51,2 & 49 & 1,7 \\
$\mathbf{2 0 1 2}$ & 3342 & 1.230 & 36,8 & 395 & 11,8 & 1.664 & 49,8 & 53 & 1,6 \\
$\mathbf{2 0 1 4}$ & 3748 & 1.080 & 28,8 & 549 & 14,6 & 2.061 & 55,0 & 58 & 1,5 \\
$\mathbf{2 0 1 6}$ & 4177 & 1.292 & 30,9 & 703 & 16,8 & 2.106 & 50,4 & 76 & 1,8 \\
$\mathbf{2 0 1 8} * * *$ & 4290 & 1.281 & 29,9 & 741 & 17,3 & 2.186 & 51,0 & 82 & 1,9 \\
$\Delta \%$ & 155,7 & 92,6 & - & $1.352,9$ & - & 133,8 & - & 156,3 & -
\end{tabular}

Fonte: Elaboração dos autores com base nos dados GEOCAPES.

* Contabilizados 5 Programas com MP/MA.

** Contabilizados 44 Programas com MP/MA/DA.

*** Contabilizado 1 Programa com MP/MA/DA.

*** Não está contabilizado 1 Programa com Doutorado Profissional.

Ao considerarmos a distribuição percentual em cada ano identificamos que se ampliou significativamente a participação de Programas de Mestrado Profissional. Em 2002, apenas 3,0\% do total de Programas eram em tal modalidade, já em 2018 esse índice passou para 17,3\%. Isso se deve também em função da menor expansão dos Programas com Mestrado Acadêmico, reduzindo a participação destes em quase $10 \%$, passando de $39,5 \%$ para $29,9 \%$, entre os anos analisados. O índice de Programas com Mestrado e Doutorado apresentou pequena redução, com a permanência ainda de mais de 50\% da totalidade dos Programas existentes (exceto em 2012). Os Programas somente com Doutorado apresentam o mesmo percentual de participação, $1,9 \%$, com pequenas as oscilações sofridas ao longo dos anos.

O elevado crescimento dos Mestrados Profissionais revela uma expansão tendenciada à Pós-Graduação demandada pelo mercado, já que esses mestrados objetivam, no geral, a qualificação de profissionais para a produção de pesquisas de inovação cujos resultados possuam efeitos diretos e rentáveis. Mancebo, Vale e Martins (2015) analisam que, nessa lógica, “[...] a pesquisa científica e tecnológica é base para a inovação e para a formação de recursos humanos qualificados, com impactos significativos no crescimento e na geração de riquezas.” (p. 46). Esse quadro reflete a opção política de desenvolvimento econômico via inovação tecnológica produzida na Pós-Graduação, com ênfase nos Mestrados Profissionais.

Na Tabela 2 estão dispostos dados sobre a distribuição regional do total de Programas, no período em análise. Os dados evidenciam que a expansão foi mais intensa nas regiões Norte, Centro-Oeste e Nordeste, $374 \%, 257,1 \%$ e 243,8\%, respectivamente. O Sul teve expansão em 
$184 \%$, ou seja, também acima da média nacional (que foi 155,7\%, conforme exposto na Tabela 1). A região Sudeste foi a que apresentou menor índice de expansão $(99,9 \%)$.

Tabela 2: Número de Programas de Pós-Graduação, por região brasileira (2002-2018)

\begin{tabular}{c|c|c|c|c|c|c|c|c|c|c}
\multirow{2}{*}{ Ano } & \multicolumn{2}{|c|}{ Norte } & \multicolumn{2}{c|}{ Nordeste } & \multicolumn{2}{c|}{ Centro-oeste } & \multicolumn{2}{c|}{ Sudeste } & \multicolumn{2}{c}{ Sul } \\
\cline { 2 - 11 } & Num. & \% & Num. & \% & Num. & \% & Num. & \% & Num. & \% \\
\hline $\mathbf{2 0 0 2}$ & 50 & 3,0 & 251 & 14,9 & 98 & 5,8 & 958 & 56,9 & 326 & 19,4 \\
\hline $\mathbf{2 0 0 4}$ & 67 & 3,5 & 306 & 15,9 & 121 & 6,3 & 1056 & 54,7 & 380 & 19,7 \\
\hline $\mathbf{2 0 0 6}$ & 93 & 4,1 & 386 & 17,0 & 156 & 6,9 & 1181 & 52,1 & 449 & 19,8 \\
\hline $\mathbf{2 0 0 8}$ & 110 & 4,3 & 457 & 17,8 & 183 & 7,1 & 1297 & 50,5 & 520 & 20,3 \\
\hline $\mathbf{2 0 1 0}$ & 133 & 4,7 & 535 & 18,8 & 207 & 7,3 & 1381 & 48,6 & 584 & 20,6 \\
\hline $\mathbf{2 0 1 2}$ & 172 & 5,1 & 657 & 19,7 & 268 & 8,0 & 1562 & 46,7 & 683 & 20,4 \\
\hline $\mathbf{2 0 1 4}$ & 195 & 5,2 & 744 & 19,9 & 306 & 8,2 & 1718 & 45,8 & 785 & 20,9 \\
\hline $\mathbf{2 0 1 6}$ & 227 & 5,4 & 846 & 20,3 & 340 & 8,1 & 1875 & 44,9 & 889 & 21,3 \\
\hline $\mathbf{2 0 1 8}$ & 237 & 5,5 & 863 & 20,1 & 350 & 8,2 & 1915 & 44,6 & 926 & 21,6 \\
\hline$\Delta \%$ & 374,0 & - & 243,8 & - & 257,1 & - & 99,9 & - & 184,0 & - \\
\hline
\end{tabular}

Fonte: Elaboração dos autores com base nos dados GEOCAPES.

Os dados evidenciam melhorias na participação das regiões periféricas no cenário nacional. O Norte passou de 3\% para 5,5\% e o Nordeste saiu de 14,9\% para 20,1\%. Também as regiões Centro-Oeste e Sul ampliaram seus índices, com uma mudança, respectivamente, de $5,8 \%$ e $19,4 \%$ para 8,2 e $21,6 \%$. Isso ocasionou a redução do percentual de Programas no Sudeste, que caiu em 12,3\%, e um alcance, em 2018, 44,6\% de participação no contexto nacional.

Ainda que tais números evidenciem redução na desigualdade da oferta da PósGraduação entre as regiões, precisa-se também avaliar a distribuição da população brasileira (IBGE, 2011). Assim, ao comparar a participação populacional das regiões Norte (população: $8,3 \%$ ) e Centro-Oeste (população: 7,4\%), verifica-se que a primeira, apesar ter maior percentual nesse indicador, dispõe de menor fração de programas de Pós-Graduação, em 2018.

No mesmo sentido, seguem-se desigualdades ao relacionar a população e programas stricto sensu entre Nordeste (população: 27,8\%) e Sul (população: 14,4\%). Embora o Nordeste concentre população consideravelmente superior ao Sul, esta última região tem participação maior em programas de Pós-Graduação, em 2018, como visto na Tabela 2. Diante disso, notase a permanência de um acesso desigual a esse nível de ensino entre as populações das grandes regiões.

Outro indicador importante para essa análise é a expansão da Pós-Graduação em números absolutos. Foi no Sudeste que se registrou o maior número de novos Programas (957), 
seguido do Nordeste (612), Sul (600) e Centro-Oeste (252). O Norte apresentou a menor expansão em termos absolutos (187). Isso nos permite concluir que a acentuada ampliação percentual dos Programas no Norte, como já indicamos, ocorreu, sobretudo, em função do limitado atendimento que a região detinha em 2002, com apenas 50 Programas.

Além do total de Programas, é fundamental avaliarmos a distribuição dos cursos que os compõem. As tabelas a seguir apresentam os dados detalhados de MA, MP e DA:

Tabela 3: Número de Cursos de Mestrado Acadêmico, Brasil e regiões (2002-2018)

\begin{tabular}{c|c|c|c|c|c|c|c|c|c|c|c}
\multirow{2}{*}{ Ano } & \multirow{2}{*}{ Brasil } & \multicolumn{2}{|c|}{ Norte } & \multicolumn{2}{c}{ Nordeste } & \multicolumn{2}{c}{ Centro-oeste } & \multicolumn{2}{c|}{ Sudeste } & \multicolumn{2}{c}{ Sul } \\
\cline { 3 - 12 } & & Num. & \% & Num. & \% & Num. & \% & Num. & \% & Num. & \% \\
\hline $\mathbf{2 0 0 2}$ & 1600 & 47 & 2,9 & 239 & 14,9 & 92 & 5,8 & 907 & 56,7 & 315 & 19,7 \\
\hline $\mathbf{2 0 0 4}$ & 1782 & 63 & 3,5 & 284 & 15,9 & 110 & 6,2 & 969 & 54,4 & 356 & 20,0 \\
\hline $\mathbf{2 0 0 6}$ & 2069 & 87 & 4,2 & 346 & 16,7 & 142 & 6,9 & 1079 & 52,2 & 415 & 20,1 \\
\hline $\mathbf{2 0 0 8}$ & 2313 & 102 & 4,4 & 409 & 17,7 & 166 & 7,2 & 1162 & 50,2 & 474 & 20,5 \\
\hline $\mathbf{2 0 1 0}$ & 2544 & 123 & 4,8 & 477 & 18,8 & 187 & 7,4 & 1228 & 48,3 & 529 & 20,8 \\
\hline $\mathbf{2 0 1 2}$ & 2894 & 148 & 5,1 & 570 & 19,7 & 240 & 8,3 & 1338 & 46,2 & 598 & 20,7 \\
\hline $\mathbf{2 0 1 4}$ & 3141 & 161 & 5,1 & 637 & 20,3 & 263 & 8,4 & 1415 & 45,0 & 665 & 21,2 \\
\hline $\mathbf{2 0 1 6}$ & 3398 & 182 & 5,4 & 703 & 20,7 & 286 & 8,4 & 1491 & 43,9 & 736 & 21,7 \\
\hline $\mathbf{2 0 1 8}$ & 3467 & 188 & 5,4 & 710 & 20,5 & 290 & 8,4 & 1510 & 43,6 & 769 & 22,2 \\
\hline$\Delta \%$ & 116,7 & 300,0 & - & 197,1 & - & 215,2 & - & 66,5 & - & 144,1 & - \\
\hline
\end{tabular}

Fonte: Elaboração dos autores com base nos dados GEOCAPES.

Na análise da Tabela 3, é importante destacar que todos os índices de expansão estão abaixo daqueles apresentados na evolução dos Programas (tabela 1 e 2), ainda assim há considerável expansão. No Brasil, o quantitativo de tais cursos evoluiu 116,7\%, sendo que regionalmente a sequência de crescimento é a mesma registrada na Tabela 2 (número de Programas por região). Assim, foi a região Norte que revelou maior crescimento percentual (300\%), seguida pelo Centro-Oeste (215,2\%), Nordeste (197,1\%), Sul (144,1\%) e Sudeste (66,5\%). A distribuição regional desses cursos também apresenta, em todos os anos, percentuais aproximados daqueles apresentados pelos Programas.

Em termos absolutos, o crescimento de cursos de Mestrados Acadêmicos foi de 1.867. A ordem de crescimento também seguiu a tendência dos Programas. Foi o Sudeste que mais cresceu (603), seguido do Nordeste (471), Sul (454), Centro-Oeste (198) e Norte (141). Novamente a acentuada expansão na região Norte, que amplia sua participação nacional em 2,5\% (alcançando o índice de 5,4\%) é motivada principalmente pelo reduzido número de cursos em 2002, somente 47. 
Iniciaremos, então, a análise dos cursos de Mestrados Profissionais. A Tabela 5 nos permite identificar que foram esses que tiveram mais acentuada expansão. Os índices são consideravelmente superiores aos registrados nos cursos acadêmicos.

Tabela 4: Número de Cursos de Mestrado Profissional, Brasil e regiões (2002-2018)

\begin{tabular}{c|c|c|c|c|c|c|c|c|c|c|c}
\multirow{2}{*}{ Ano } & \multirow{2}{*}{ Brasil } & \multicolumn{2}{|c|}{ Norte } & \multicolumn{2}{c|}{ Nordeste } & \multicolumn{2}{c|}{ Centro-oeste } & \multicolumn{2}{c|}{ Sudeste } & \multicolumn{2}{|c}{ Sul } \\
\cline { 3 - 12 } & & Num. & \% & Num. & \% & Num. & \% & Num. & \% & Num. & \% \\
\hline $\mathbf{2 0 0 2}$ & 100 & 3 & 3,0 & 14 & 14,0 & 9 & 9,0 & 54 & 54,0 & 20 & 20,0 \\
\hline $\mathbf{2 0 0 4}$ & 117 & 3 & 2,6 & 16 & 13,7 & 10 & 8,5 & 70 & 59,8 & 18 & 15,4 \\
\hline $\mathbf{2 0 0 6}$ & 157 & 4 & 2,5 & 30 & 19,1 & 12 & 7,6 & 82 & 52,2 & 29 & 18,5 \\
\hline $\mathbf{2 0 0 8}$ & 218 & 6 & 2,8 & 36 & 16,5 & 15 & 6,9 & 119 & 54,6 & 42 & 19,3 \\
\hline $\mathbf{2 0 1 0}$ & 247 & 7 & 2,8 & 41 & 16,6 & 16 & 6,5 & 132 & 53,4 & 51 & 20,6 \\
\hline $\mathbf{2 0 1 2}$ & 395 & 20 & 5,1 & 70 & 17,7 & 23 & 5,8 & 203 & 51,4 & 79 & 20,0 \\
\hline $\mathbf{2 0 1 4}$ & 549 & 29 & 5,3 & 92 & 16,8 & 37 & 6,7 & 278 & 50,6 & 113 & 20,6 \\
\hline $\mathbf{2 0 1 6}$ & 703 & 41 & 5,8 & 128 & 18,2 & 46 & 6,5 & 345 & 49,1 & 143 & 20,3 \\
\hline $\mathbf{2 0 1 8}$ & 741 & 46 & 6,2 & 138 & 18,6 & 49 & 6,6 & 362 & 48,9 & 146 & 19,7 \\
\hline$\Delta \%$ & 641,0 & $1.433,3$ & - & 885,7 & - & 444,4 & - & 570,4 & - & 630,0 & - \\
\hline
\end{tabular}

Fonte: Elaboração dos autores com base nos dados GEOCAPES.

No Brasil, o crescimento foi de $641 \%$, com 641 novos cursos. Novamente o Norte apresentou maior crescimento percentual, com a incrível cifra de 1.433,3\%. Ainda que o número de novos cursos seja apenas 43 (a segunda menor expansão absoluta), alcançando 6,2\% de participação nacional em 2018 (índice superior aos registrados no número de Programas e cursos acadêmicos). Em termos percentuais, a segunda maior expansão foi registrada no Nordeste, $885,7 \%$, seguido do Sul, 630\%, uma vez que o crescimento absoluto nessas regiões foram próximos, 124 e 126 novos cursos, respectivamente. Diferentemente dos outros indicadores analisados, o Centro-Oeste apresentou menor expansão em termos relativos, $444,4 \%$ (ainda assim muito elevado) e números absolutos (40 novos cursos). O Sudeste atingiu $570,4 \%$, equivalente a 308 cursos.

No que tange à distribuição regional dos Mestrados Profissionais, observamos que, com pequenas variações, os números registrados em 2018 são próximos aos índices apresentados no caso dos Programas (Tabela 2) e dos cursos de Mestrados Acadêmicos (Tabela 3). No entanto, algumas questões merecem destaque em relação aos indicadores já analisados: a) é a maior participação do Norte $(6,2 \%)$; b) também é acentuada a concentração no Sudeste $(48,9 \%)$; c) no Nordeste o crescimento $(18,6 \%)$ foi inferior aos registrados na distribuição de Programas e Mestrados Acadêmicos; d) são os menores índices de participação registrados pelas regiões Centro-Oeste (6,6\%) e Sul (19,7\%); e) Norte e Nordeste possuem quase $25 \%$ dos cursos, índice próximo ao registrado na distribuição de Programas e Mestrados Acadêmicos. 
A Tabela 5 expõe a evolução dos cursos de Doutorado Acadêmico. Os dados apontam crescimento nacional de 134,5\%. Também está no Norte o maior índice de expansão: 425\%, sendo, porém, a região que novamente apresenta menor crescimento em termos absolutos, com 68 novos cursos, passando de 16 em 2002 para 84 em 2018. Ainda que o Sudeste apresente também o menor índice de crescimento, com 78,4\%, foi a região que em termos absolutos mais cresceu -515 cursos.

Tabela 5: Número de Cursos de Doutorado Acadêmico, Brasil e regiões (2002-2018)

\begin{tabular}{c|c|c|c|c|c|c|c|c|c|c|c}
\multirow{2}{*}{ Ano } & \multirow{2}{*}{ Brasil } & \multicolumn{2}{|c|}{ Norte } & \multicolumn{2}{c}{ Nordeste } & \multicolumn{2}{c}{ Centro-oeste } & \multicolumn{2}{c}{ Sudeste } & \multicolumn{2}{c}{ Sul } \\
\cline { 3 - 12 } & & Num. & \% & Num. & \% & Num. & \% & Num. & \% & Num. & \% \\
\hline $\mathbf{2 0 0 2}$ & 967 & 16 & 1,7 & 100 & 10,3 & 36 & 3,7 & 657 & 67,9 & 158 & 16,3 \\
\hline $\mathbf{2 0 0 4}$ & 1055 & 20 & 1,9 & 113 & 10,7 & 46 & 4,4 & 692 & 65,6 & 184 & 17,4 \\
\hline $\mathbf{2 0 0 6}$ & 1185 & 25 & 2,1 & 140 & 11,8 & 58 & 4,9 & 753 & 63,5 & 209 & 17,6 \\
\hline $\mathbf{2 0 0 8}$ & 1320 & 35 & 2,7 & 172 & 13,0 & 74 & 5,6 & 797 & 60,4 & 242 & 18,3 \\
\hline $\mathbf{2 0 1 0}$ & 1502 & 44 & 2,9 & 210 & 14,0 & 92 & 6,1 & 866 & 57,7 & 290 & 19,3 \\
\hline $\mathbf{2 0 1 2}$ & 1717 & 54 & 3,1 & 256 & 14,9 & 111 & 6,5 & 953 & 55,5 & 343 & 20,0 \\
\hline $\mathbf{2 0 1 4}$ & 2119 & 78 & 3,7 & 327 & 15,4 & 153 & 7,2 & 1111 & 52,4 & 450 & 21,2 \\
\hline $\mathbf{2 0 1 6}$ & 2182 & 82 & 3,8 & 335 & 15,4 & 159 & 7,3 & 1143 & 52,4 & 463 & 21,2 \\
\hline $\mathbf{2 0 1 8}$ & 2268 & 84 & 3,7 & 361 & 15,9 & 167 & 7,4 & 1172 & 51,7 & 484 & 21,3 \\
\hline$\Delta \%$ & 134,5 & 425,0 & - & 261,0 & - & 363,9 & - & 78,4 & - & 206,3 & - \\
\hline
\end{tabular}

Fonte: Elaboração dos autores com base nos dados GEOCAPES.

Centro-Oeste foi a região que também teve elevada expansão percentual na quantidade de cursos de Doutorado Acadêmico, mas, em termos absolutos, foi a segunda menor em crescimento, com 131 novos cursos. O Nordeste tem crescimento relativo superior ao Sul, respectivamente, $261 \%$ e $206 \%$, mas registrou crescimento absoluto inferior, com 261 novos cursos, tendo a região Sul se expandido em 326.

Cabe ressaltarmos que são nos cursos de Doutorado Acadêmico que se evidencia a menor participação das regiões Norte e Nordeste no contexto nacional. Ainda que tenham ampliado seus índices no período analisado, em 2018, somente 3,7\% desses cursos estavam no Norte e 15,9\% no Nordeste. O Centro-Oeste dobrou o percentual de participação, alcançando 7,4\%. A região Sul também ampliou seu índice, saiu de 16,3\% para 21,3\%. Os crescimentos registrados no Centro-Oeste e Sul permitiram que essas regiões apresentassem, no final do período em análise, percentuais equivalentes aos registrados na distribuição de Programas e de cursos de Mestrado Acadêmico. O Sudeste, mesmo com a redução em 16,2\%, detinha em 2018 ainda mais da metade dos cursos de Doutorado Acadêmico do país. Juntos, Sudeste e Sul alcançaram mais de $70 \%$ de tais cursos, enquanto o Norte e Nordeste somaram menos de $20 \%$. 
Em suma, é na oferta de Doutorados Acadêmicos que se manifesta a maior desigualdade regional na Pós-Graduação Stricto Sensu brasileira.

Realizada a análise sobre a expansão e distribuição regional de Programas e Cursos de Pós-Graduação no Brasil, discutiremos os dados relacionados ao seu financiamento, considerando particularmente o orçamento da CAPES, que conforme já indicado é o principal órgão estatal para fomento deste nível educacional.

\section{Financiamento da CAPES para pesquisadores e estudantes}

O processo de expansão e financiamento da Pós-Graduação deve ser compreendido no contexto das políticas sociais, ou negação dessas, no capitalismo contemporâneo. Assim, é oportuno consideramos a conjuntura econômica e seus nexos com condução política do Brasil no período em estudo. Dito de outra forma, precisamos identificar as implicações das medidas neoliberais, implementadas por aqui a partir da década de 1990, para as políticas sociais em geral, para a educação e a Pós-Graduação em particular.

De acordo com os preceitos neoliberais, é preciso que reduza o papel estatal no financiamento de políticas sociais e ampliar sua atuação para garantia do livre mercado. No campo educacional deve-se estimular o crescimento da rede privada e redefinir o financiamento público. Atribui-se como responsabilidade individual os gastos com a educação, particularmente no âmbito do ensino superior. Tal concepção ganha lastro nos países periféricos do capitalismo global a partir de orientações emanadas por Organismos Financeiros Internacionais, com destaque para o Banco Mundial (SGUISSARDI, 2009).

Conforme destaca Behring (2012), as políticas neoliberais são implementadas no Brasil a partir década de 1990, com o governo Fernando Collor de Melo (1990-1992). Mas será no governo Fernando Henrique Cardoso (1995-2002) que tal projeto ganha efetividade, tendo como eixo central desse movimento a criação do Ministério da Administração Federal e da Reforma do Estado (MARE). O propósito central consistia em adequar o aparelho estatal às novas demandas da economia globalizada, conforme proposto em seu Plano Diretor de Reforma do Estado (PDRE).

Esse projeto foi mantido nos governos Lula da Silva (2003-2010) e Dilma Rousseff (2011-2016), com políticas econômicas subordinadas aos interesses do capital. No entanto, em tais governos também se buscou garantir medidas sociais, voltadas particularmente a frações de setores sociais mais vulneráveis e excluídos, que atenuavam as implicações do projeto 
neoliberal. A viabilidade desse movimento se deu em função do período de crescimento econômico vivenciado em tais governos.

Essa perspectiva de conciliação de classes evidenciou suas ruínas com os impactos da crise econômica global, desencadeada em 2008, especialmente a partir do segundo mandato de Dilma Rousseff, iniciado em 2014. Ganhou centralidade no discurso governamental a necessidade de "ajuste fiscal". Para resolver o pretexto de resolver a crise capitalista, gerada pelo próprio sistema, implementam-se medidas que a redução do orçamento social em detrimento da política econômica rentista, indispensável para a valorização do capital.

O Estado brasileiro apresentou superávits fiscais primários (receitas menos despesas correntes) durante mais de 10 anos: de 1999 a 2013; somente a partir de 2014 passou a apresentar déficits primários, em razão da crise econômica e de políticas equivocadas de desoneração fiscal ao grande capital - que reduziram as receitas arrecadadas. $\mathrm{O}$ ajuste fiscal iniciado nesse mesmo ano pelo Governo Dilma, e aprofundado pelo Governo Temer, jogou o país em uma recessão e piorou, ainda mais, as contas públicas, em razão de novas quedas na arrecadação, motivadas pelo baixo nível de atividade econômica. (DRUCK; FILGUEIRAS; MOREIRA, 2017, p. 606).

Com isso, as medidas antissociais de cunho neoliberal foram intensificadas com Michel Temer, que, ao assumir a Presidência da República, proporcionou maior celeridade nas políticas de ajustes fiscal. Como destaca Mancebo (2017, p. 880), essa é a perspectiva sintetizada no Documento "Uma ponte para o futuro", elaborado pelo Partido de Michel Temer, para “aprofundar o papel do 'Estado mínimo', enxuto e supostamente eficiente; incrementar a participação da iniciativa privada; flexibilizar o mercado de trabalho e ampliar a concorrência internacional, abrindo de maneira escancarada as portas para a venda do patrimônio nacional". Em nossa perspectiva, um desfecho trágico do projeto de conciliação de classes sociais, com a deposição da presidenta Dilma Rousseff, em 2016.

No governo Michel Temer, o marco principal deste processo é a Emenda à Constituição N. 95/2016, que instituiu um Novo Regime Fiscal no Brasil, por 20 anos. Com essa medida impede-se a ampliação do orçamento público federal destinados às políticas sociais para garantia do superávit primário: ampliação dos gastos com a chamada dívida pública. Evidencia-se, assim, o papel do Estado na garantia da valorização do capital ao não estabelecer, com essa medida, "nenhum limite ao pagamento de juros, encargos e amortização da dívida, o que se materializou, depois, na LOA 2017 ao elevar substancialmente, 60,2\%, o valor possível para essa despesa em relação ao executado em 2016." (AMARAL, 2017, p. 24).

Essa também é a política econômica que baliza o governo Jair Bolsonaro (iniciado em 2019). Assim, tende-se a ampliar a margem de apropriação do fundo público pelo capital em 
detrimento das políticas sociais. Esse movimento certamente reduzirá ainda mais orçamento no financiamento da educação pública. Entretanto, é fundamental destacar que o cerne dessa política já se fazia presente nos governos anteriores.

Em análise sobre o orçamento federal destinado às instituições públicas mantidas pela União, Chaves e Amaral (2014, p. 46) evidenciam que "a diferença entre o aumento do percentual de recursos arrecadados de impostos que atingiu 193,0\% no período de 1989 (pósCF de 1988) a 2012 e o percentual de aumento das despesas liquidadas para as IFES que ficou em 104,0\%, no mesmo período”. Na mesma perspectiva, Guimarães, Chaves e Novais (2018) concluem que a prioridade dos últimos governos brasileiros tem sido a política econômica de valorização do capital, com volumosos recursos para juros e encargos da dívida pública. No período 2003-2017,

Os gastos com a dívida são tão exorbitantes [...] que representam em média $8,24 \%$ do PIB. Ainda que, em 2017, esse percentual $(8,34 \%)$ seja inferior ao índice de $2003(8,96 \%)$, isso não representou menos recursos para a dívida, tendo em vista o crescimento do PIB em 69,26\%. O maior volume de recursos para a dívida em relação ao PIB se deu em 2006, com $11,45 \%$, seguido de 2009, com 11,43\%; e o menor índice foi em 2011, com 5,5\%. Mesmo com a queda do PIB, a partir de 2014, os índices praticados mantiveram-se elevados, com destaque para o ano de 2017, evidenciando a manutenção e aprofundamento da política econômica. (GUIMARÃES; CHAVES; NOVAIS, 2018, p. 252).

Tal processo tem implicações diretas para o financiamento das políticas sociais. Considerando os objetivos do presente estudo, analisaremos o movimento da execução orçamentária do MEC e da CAPES.

Tabela 6: Evolução da Execução Orçamentária do MEC e da CAPES (2002-2018)

\begin{tabular}{|c|c|c|c|c|c|}
\hline \multirow{2}{*}{ Ano } & \multicolumn{2}{|l|}{ MEC (a) } & \multicolumn{2}{|c|}{ CAPES (b) } & \multirow{2}{*}{$\begin{array}{c}\% \\
\text { (b)/(a) }\end{array}$} \\
\hline & $\mathbf{R} \$$ & VA\% & $\mathbf{R} \$$ & VA\% $\%$ & \\
\hline 2002 & 44.966 .781 .893 & - & 1.404 .728 .898 & - & 3,1 \\
\hline 2004 & 40.588 .486 .989 & $-9,7$ & 1.249 .853 .274 & $-11,0$ & 3,1 \\
\hline 2006 & 47.432 .682 .945 & 16,9 & 1.456 .630 .854 & 16,5 & 3,1 \\
\hline 2008 & 59.757 .885 .598 & 26,0 & 2.281 .784 .999 & 56,6 & 3,8 \\
\hline 2010 & 89.070 .914 .222 & 49,1 & 3.284 .194 .339 & 43,9 & 3,7 \\
\hline 2012 & 110.908 .350 .592 & 24,5 & 5.168 .735 .149 & 57,4 & 4,7 \\
\hline 2014 & 119.848 .451 .059 & 8,1 & 7.219 .585 .895 & 39,7 & 6,0 \\
\hline 2016 & 99.369 .819 .365 & $-17,1$ & 5.528 .565 .744 & $-23,4$ & 5,6 \\
\hline 2018 & 104.996 .119 .204 & 5,7 & 3.405 .851 .663 & $-38,4$ & 3,2 \\
\hline$\Delta \%$ & 133,5 & - & 142,5 & - & - \\
\hline
\end{tabular}

Fonte: Elaboração dos autores com base na Execução Orçamentária da União Em R\$ 1,00; com valores atualizados pelo IPCA, jan. 2019. 
No período analisado, os dados apontam crescimento de $133,5 \%$ no orçamento do MEC. Para a CAPES, a ampliação foi ligeiramente maior, 142,5\%. Cabe observar que entre 2002-2004 ocorreu redução orçamentária no financiamento de ambos os órgãos - 9,7\% e 11\%, respectivamente. De 2004 até 2014 identificamos um período de crescimento acentuado no orçamento, particularmente da CAPES: isso possibilitou que esse órgão se atinge, em 2014, 6\% dos recursos destinados ao MEC.

O maior volume de recurso foi registrado em 2014. A partir de então, com o aprofundamento da política de ajuste fiscal, como já analisado, houve redução orçamentária do MEC e principalmente da CAPES. Isso ocasiona, consequentemente, grandes riscos para a manutenção da Pós-Graduação Stricto Sensu, particularmente para seu processo de expansão. Os Gráficos 1 e 2 nos permitem perceber visualmente a movimentação dos orçamentos.

Gráfico 1: Evolução da Execução Orçamentária do Ministério da Educação (2002-2018)

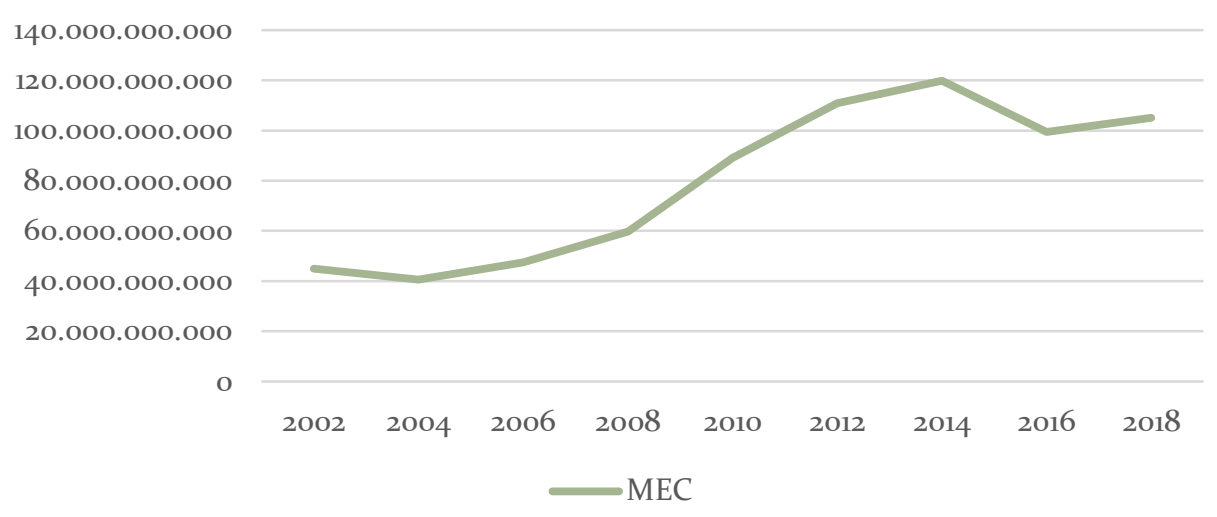

Fonte: Elaboração dos autores com base nos dados da Execução Orçamentária da União. Em R\$ 1,00; com valores atualizados pelo IPCA, jan. 2019.

Gráfico 2: Evolução da Execução Orçamentária da CAPES (2002-2018)

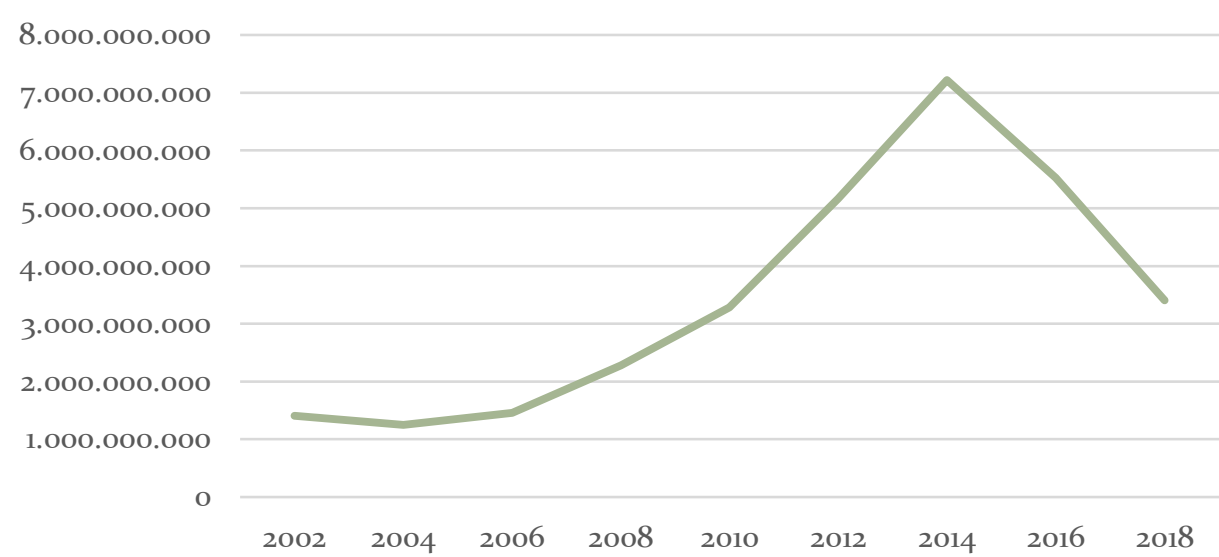

Fonte: Elaboração dos autores com base nos dados da Execução Orçamentária da União. Em R\$ 1,00; com valores atualizados pelo IPCA, jan. 2019. 
O orçamento da CAPES carrega consigo todo um segmento ligado a produção de conhecimento, sobretudo no que tange ao financiamento mais direto de pesquisadores e estudantes. Ainda que tais auxílios não sejam exclusivos para a Pós-Graduação ${ }^{5}$, a análise dos mesmos também nos auxilia compreender o financiamento dos cursos de mestrado e doutorado no país. A Tabela 7 demonstra que a evolução orçamentária que tange aos auxílios financeiros para pesquisadores e estudantes foi mais acentuada que o movimento registrado no MEC e CAPES.

Tabela 7: Evolução da Execução Orçamentária da CAPES em Auxílios Financeiros para pesquisadores e estudantes (2002-2018)

\begin{tabular}{c|c|c|c|c|c|c}
\multirow{2}{*}{ Ano } & \multicolumn{2}{|c|}{ Pesquisadores } & \multicolumn{2}{c}{ Estudantes } & \multicolumn{2}{c}{ Total } \\
\cline { 2 - 7 } & $\mathbf{R} \$$ & VA\% & R\$ & VA\% & R\$ & VA\% \\
\hline $\mathbf{2 0 0 2}$ & 57.589 .032 & - & 980.675 .509 & - & 1.038 .264 .540 & - \\
\hline $\mathbf{2 0 0 4}$ & 58.296 .484 & 1,2 & 828.836 .865 & $-15,5$ & 887.133 .349 & $-14,6$ \\
\hline $\mathbf{2 0 0 6}$ & 130.663 .422 & 124,1 & 912.289 .276 & 10,1 & 1.042 .952 .699 & 17,6 \\
\hline $\mathbf{2 0 0 8}$ & 287.973 .617 & 120,4 & 1.065 .758 .136 & 16,8 & 1.353 .731 .753 & 29,8 \\
\hline $\mathbf{2 0 1 0}$ & 395.716 .307 & 37,4 & 1.608 .801 .263 & 51,0 & 2.004 .517 .570 & 48,1 \\
\hline $\mathbf{2 0 1 2}$ & 466.694 .430 & 17,9 & 3.569 .633 .080 & 121,9 & 4.036 .327 .509 & 101,4 \\
\hline $\mathbf{2 0 1 4}$ & 392.917 .600 & $-15,8$ & 5.830 .043 .554 & 63,3 & 6.222 .961 .154 & 54,2 \\
\hline $\mathbf{2 0 1 6}$ & 255.278 .618 & $-35,0$ & 4.455 .441 .537 & $-23,6$ & 4.710 .720 .155 & $-24,3$ \\
\hline $\mathbf{2 0 1 8}$ & 193.948 .625 & $-24,0$ & 2.547 .515 .396 & $-42,8$ & 2.741 .464 .021 & $-41,8$ \\
\hline$\Delta \%$ & 236,8 & - & 159,8 & - & 164,0 & -
\end{tabular}

Fonte: Elaboração dos autores com base na Execução Orçamentária da União Em R \$ 1,00; com valores atualizados pelo IPCA, jan. 2019.

A evolução orçamentária total foi de $164 \%$. Neste caso, o movimento inicial e final, com registro de redução financeira, é semelhante ao registrado no orçamento da CAPES. Maior variação de crescimento foi registrada em 2012, com 101,4\%, a maior diminuição foi registrada em 2018, com 41,8\%. Com a redução orçamentária, identificamos que o valor destinado no ano final de análise é pouco acima do praticado em 2010.

O maior índice relativo de expansão foi registrado no financiamento de pesquisadores, $236,8 \%$, sendo que o montante em tal rubrica é bastante inferior ao praticado em relação ao financiamento de estudantes. O maior crescimento percentual se deu entre os anos de 2006 e 2008. Observamos que em 2014 registrou-se queda em relação ao orçamento

\footnotetext{
5 Tais auxílios não estão necessariamente vinculados à Pós-Graduação, pois há projetos executados pela CAPES que atuam no âmbito da graduação e/ou educação básica.
} 
praticado em 2012, a qual se acentua nos anos subsequentes. O orçamento executado em 2018 foi consideravelmente abaixo do registrado em 2008.

O orçamento de auxílios para estudantes expandiu em 159,8\%, menor índice relativo registrado. O maior crescimento foi registrado em 2012, com 121,9\% em relação a 2010. Assim como ocorreu no orçamento do MEC e CAPES, há redução orçamentária entre 2002 e 2004, bem como se registra tendência negativa a partir de 2014. Em 2018, com índice de perda acumulada acima de $60 \%$, em 4 anos, o valor executado foi abaixo do registrado em 2012.

O movimento orçamentário dos auxílios financeiros analisados pode ser melhor percebido nos gráficos a seguir.

Gráfico 3: Evolução da Execução Orçamentária da CAPES em auxílios financeiros a Estudantes no Brasil (2002-2018)

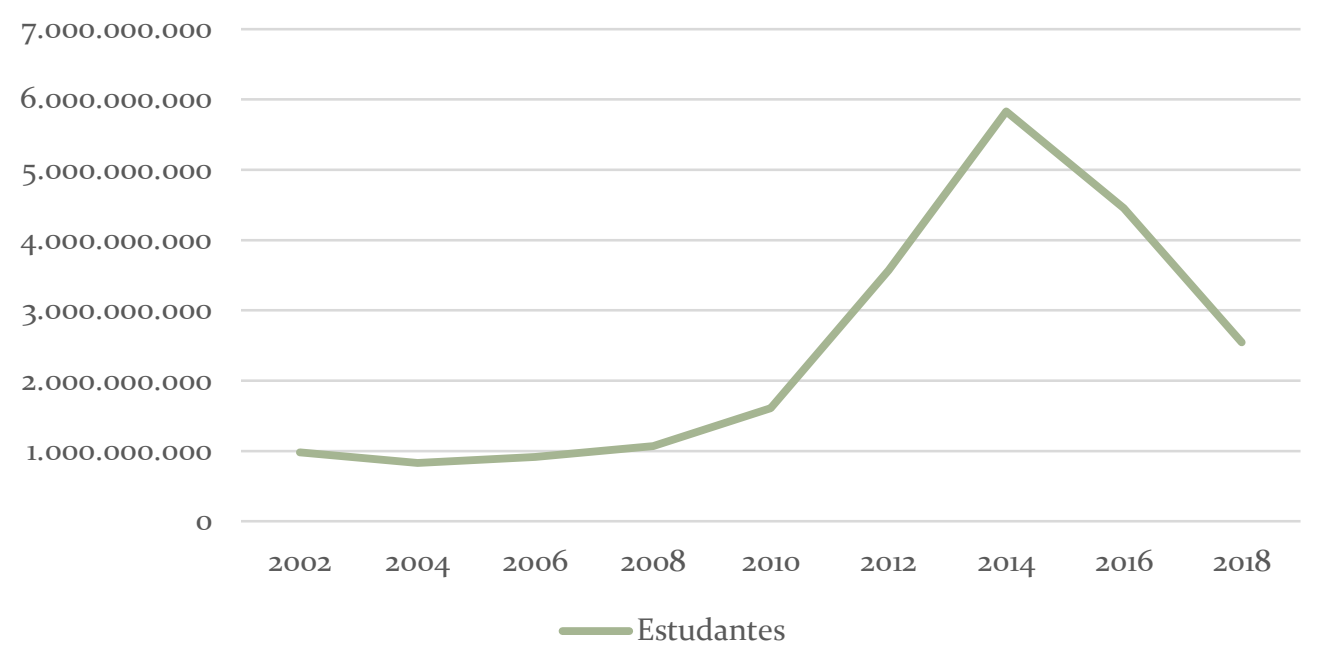

Fonte: Elaboração dos autores com base nos dados da Execução Orçamentária da União. Em R\$ 1,00; com valores atualizados pelo IPCA, jan. 2019.

O gráfico acima revela que os auxílios financeiros a estudantes seguem em constante ampliação até o ano de 2014, quando a exemplo do gráfico 3 que versa sobre a execução orçamentária da CAPES, sofre vertiginosa queda. Os índices de 2018, final da série, atingem patamares próximos dos de 2010, conforme podemos observar no gráfico 3 .

Dinâmica semelhante podemos observar no que se refere a execução orçamentária dos auxílios financeiros a pesquisadores. Neste, o crescimento se sustenta até o ano de 2012, quando as sucessivas quedas apontam ao fim da série, índice médio entre 2006 e 2008. 
Gráfico 4: Evolução da Execução Orçamentária da CAPES em auxílios financeiros a Pesquisadores no Brasil (2002-2018)

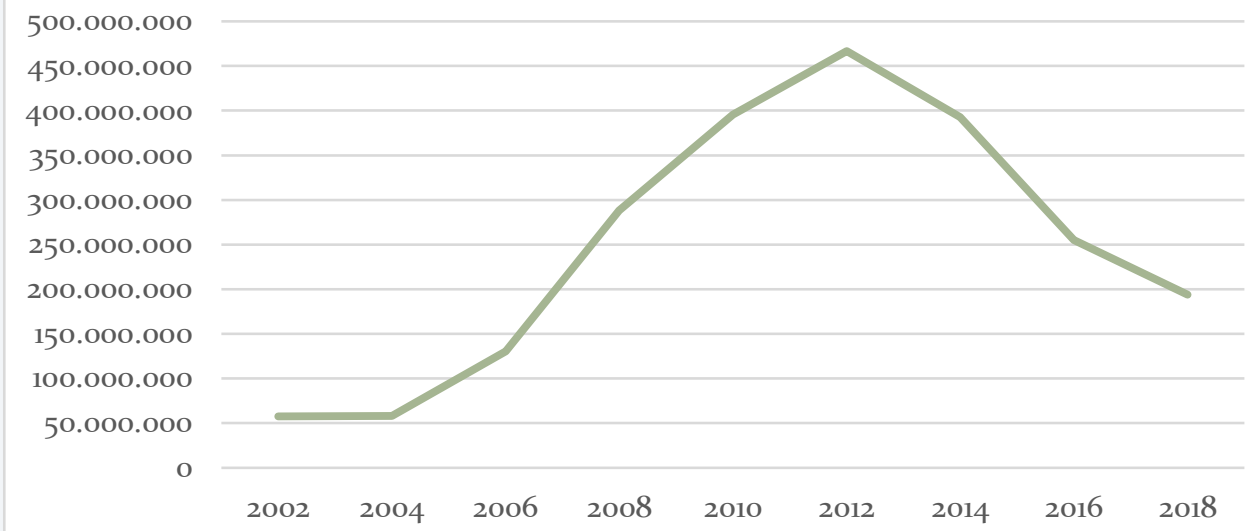

Fonte: Elaboração dos autores com base nos dados da Execução Orçamentária da União. Em R \$ 1,00; com valores atualizados pelo IPCA, jan. 2019.

Pelo exposto, identificamos que o processo de expansão da Pós-Graduação Stricto Sensu, registrado de forma positiva em todo o período analisado, não foi acompanhado da evolução contínua do orçamento público. Isso certamente implica em sérios problemas para a manutenção de tais Programas, especialmente para as instituições e regiões em que tal processo ainda está em etapa de implementação. Nesse sentido, para as regiões Norte e Nordeste o movimento tende ser ainda mais nefasto, aprofundando as assimetrias regionais.

As ações iniciais do governo Jair Bolsonaro (iniciado em 2019) indicam o aprofundamento dessa política, exemplo disso foram os cortes de recursos orçamentários das Universidades e Institutos Federais, a redução no número de bolsas de Pós-Graduação e a proposta apresentada com o nome de Programa Future-se. No âmbito específico da pesquisa, particularmente nas universidades públicas, as medidas implementadas buscam aproximá-las ainda mais da lógica do mercado, colocando o conhecimento produzido a serviço do setor produtivo.

Em nossa perspectiva, sem o necessário financiamento estatal da Pós-Graduação, especialmente para as instituições públicas, não é possível enfrentar a questão da desigualdade regional nesse nível formativo. Como bem destaca Sguissardi (2008, p. 42), “[...] apenas o Estado e seu polo público têm condições de enfrentar os problemas da diversidade regional, que se traduzem em disparidades, assimetrias e exclusão social”, pois, conclui o autor, os interesses de lucro não movimentaram o setor privado-mercantil para espaços regionais sem clientela com poder aquisitivo que lhes garantam as condições de pagar por sua formação. 


\section{Considerações Finais}

A análise realizada neste estudo mostra que a desigualdade regional no Brasil é resultado de um movimento histórico que sempre colocou às margens determinadas regiões em relação a outras. A consolidação da estrutura social, política e econômica brasileira tem como sustentação um sistema desigual, em que nos diferentes campos sociais, com destaque para a educação superior em nível de Pós-Graduação Stricto Sensu, há regiões privilegiadas de um lado e desfavorecidas de outro.

O curso do desenvolvimento no país inclinou-se para as regiões que têm os grandes polos industriais, Sul e Sudeste, tornando-as também nos centros decisórios de políticas do governo. Em contrapartida, as regiões Norte e Nordeste experienciam um processo histórico de baixo crescimento econômico e muitos problemas sociais. Esse cenário é observado na assimétrica evolução da Pós-Graduação brasileira.

Com a verificação dos dados de expansão de programas de Pós-Graduação foi possível observar que em todo o período analisado (2002-2018) as regiões Norte, Nordeste e Centro-Oeste tiveram menor participação, enquanto Sul e Sudeste apresentaram os maiores números. No primeiro ano do recorte (2002), o eixo Sul/Sudeste reunia 76,3\% dos programas stricto sensu e, em 2018, essas regiões concentraram 66,2\% dos programas, o que representa uma queda na concentração, mas não o suficiente para a superação da desigual expansão.

Como já registrado, com a política de ajuste fiscal ocorreu também um declínio no orçamento do MEC e da CAPES, o que fica bastante evidente após o ano de 2014. No mesmo período, essa política refletiu em significativo decréscimo do orçamento da CAPES em auxílios financeiros para pesquisadores e estudantes. Nota-se uma tendência negativa para o financiamento público da Pós-Graduação, reforçando a lógica neoliberal de afastamento do Estado em relação aos serviços públicos.

Em síntese, constatamos que a atual conjuntura de políticas para a expansão da PósGraduação Stricto Sensu e sua efetivação é parte da estrutura capitalista/neoliberal, carregando todas as mazelas desse sistema. Nessa direção, ainda que existam avanços pontuais na redução das assimetrias regionais, o problema permanece. Sobretudo em função das medidas de ajuste fiscal, levadas adiante pelo atual governo, é possível constatar que sem o necessário financiamento público serão aprofundadas as disparidades regionais na Pós-Graduação brasileira. 


\section{REFERÊNCIAS}

AMARAL, Nelson Cardoso. Com a PEC 241/55 (EC 95) haverá prioridade para cumprir as metas do PNE (2014-2024)? Revista Brasileira de Educação, v. 22, n. 71, 2017. Disponível em: <http://www.scielo.br/pdf/rbedu/v22n71/1809-449X-rbedu-s1413-

24782017227145.pdf >. Acesso em: dezembro de 2017.

ANDRADE, Jemina de Araujo Moraes; SIMÕES, Helena Cristina Guimarães Queiroz. Educação superior: um direito de todos? Revista Práxis Educacional, Vitória da Conquista Bahia - Brasil, v. 16, n. 37, p. 393-407, Edição Especial, 2020. Disponível em: <http://periodicos2.uesb.br/index.php/praxis/article/view/6190>. Acesso em 10 mar. 2020.

BEHRING, Elaine Rossetti. Rotação do capital e crise: fundamentos para compreender o fundo público e a política social. In: SALVADOR, Evilasio et al. (Orgs.). Financeirização, fundo público e política social. São Paulo: Cortez, 2012.

BIANCHETTI, Roberto Gerardo. Modelo neoliberal e políticas educacionais. São Paulo: Cortez, 1997.

BRASIL, Decreto n. ${ }^{\circ} 29.741$, de 11 de julho de 1951. Institui uma comissão para promover a Campanha Nacional de Aperfeiçoamento de pessoal de nível superior. Disponível em: <http://www2.camara.leg.br/legin/fed/decret/1950-1959/decreto-29741-11-julho-1951336144-norma-pe.html>. Acesso em: 1 março de 2018.

BRASIL, Decreto n. ${ }^{0} 74.299$, de 18 de julho de 1974. Dispõe sobre a Coordenação de Aperfeiçoamento de Pessoal de Nível Superior (CAPES) e dá outras providências. Disponível em: < http://www2.camara.leg.br/legin/fed/decret/1970-1979/decreto-74299-18-julho-1974422808-publicacaooriginal-1-pe.html >. Acesso em: 1 março de 2018.

BRITO, Cristiane de Sousa; GUIMARÃES, André Rodrigues. A expansão da Educação Superior e a desigualdade regional brasileira: uma análise nos marcos dos Planos Nacionais de Educação. EccoS - Rev. Cient., São Paulo, n. 44, p. 43-66, set./dez. 2017. Disponível em: <http://www4.uninove.br/ojs/index.php/eccos/article/viewFile/7898/3651>. Acesso em: 20 dez. 2019.

CENSO DEMOGRÁFICO 2010. Características da população e dos domicílios: resultados do universo. Rio de Janeiro: IBGE, 2011. Disponível em:

<https://censo2010.ibge.gov.br/sinopse/index.php?dados=5\&uf=00>. Acesso em: 18 jan. 2020.

CHAVES, Vera Lúcia Jacob; AMARAL, Nelson Cardoso. Política de financiamento da educação superior - análise dos Planos Nacionais de Educação pós-constituição/1988. Revista Eletrônica de Educação. v. 8, n. 1, 2014. Disponível em:

<http://www.reveduc.ufscar.br/index.php/reveduc/article/viewFile/1009/313>. Acesso em: 20 dez. 2019.

DRUCK, Graça; FILGUEIRAS, Luiz; MOREIRA, Uallace. Ajuste fiscal e as universidades públicas brasileiras: a nova investida do Banco Mundial. Cadernos do CEAS. n. 242, p. 602634, set./dez., 2017. Disponível em: 
<https://cadernosdoceas.ucsal.br/index.php/cadernosdoceas/article/view/411/333>. Acesso em: 10 jan. 2020.

FAUSTO, Boris. História do Brasil. 2 ed. São Paulo: Editora da Universidade de São Paulo, 1995.

FURTADO, Celso. O Capitalismo global. 7. ed. São Paulo: Paz e Terra, 1998.

GAMBOA, Sílvio Sanchez. Quantidade-qualidade: para além de um dualismo técnico e de uma dicotomia epistemológica. In: SANTOS FILHO, José Camilo dos; GAMBOA, Sílvio Sanchez (Orgs.). Pesquisa educacional: quantidade-qualidade. São Paulo: Cortez, 1995.

GUIMARÃES, André Rodrigues; CHAVES, Vera Lúcia Jacob; NOVAIS, Valéria Silva de Moraes. Financiamento das universidades públicas no Brasil no contexto de ajuste fiscal. In: CASTRO, A.; CABRAL NETO, A.; CABRITO, B.; CERDEIRA, L.; CHAVES, V. J. (Org.). Educação superior em países e regiões de língua portuguesa: desafios em tempo de crise. Lisboa: Educa, 2018.

MANCEBO, Deise. Crise político-econômica no Brasil: breve análise da educação superior. Educ. Soc., Campinas, v. 38, no . 141, p.875-892, out.-dez., 2017. Disponível em: <http://www.scielo.br/scielo.php?pid=S0101$73302017000400875 \&$ script=sci_abstract\&tlng=pt >. Acesso em: 20 dez. 2019.

MANCEBO, Deise; VALE, Andréa Araujo; MARTINS, Tânia Barbosa. Políticas de expansão da educação superior no Brasil 1995-2010. Revista Brasileira de Educação. v. 20 n. 60 jan.-mar., 2015. Disponível em: <http://www.scielo.br/pdf/rbedu/v20n60/1413-2478rbedu-20-60-0031.pdf>. Acesso em: 20 dez. 2019.

OLIVEIRA, Júlio César. Análise do crescimento econômico e das desigualdades regionais no Brasil. Estudos do CEPE, Santa Cruz do Sul, p. 5-26. ISSN 1982-6729. set. 2009. Disponível em: <https://online.unisc.br/seer/index.php/cepe/article/view/1004/764>. Acesso em: 15 out. 2019.

OXFAM. País Estagnado: um retrato das desigualdades brasileiras. São Paulo: Oxfam Brasil, 2018. Disponível em:

https://www.oxfam.org.br/sites/default/files/arquivos/relatorio_desigualdade_2018_pais_esta gnado_digital.pdf. Acesso em: 28 mai. 2019.

PRADO JÚNIOR, Caio. História econômica do Brasil. 6. ed. São Paulo: Editora Brasiliense, 1961.

SILVA JUNIOR, João dos Reis. The New Brasilian universiy: a busca por resultados comercializáveis: para quem? Bauru: Práxis, 2017.

SGUISSARDI, Valdemar. Universidade brasileira no século XXI: desafios do presente. São Paulo: Cortez, 2009.

SGUISSARDI, Valdemar. Educação superior e diversidade regional no Brasil - o privado (mercantil) como fator de desigualdade e exclusão. In: CHAVES, Vera Lúcia Jacob; SILVA 
JÚNIOR, João dos Reis. Educação Superior no Brasil e diversidade regional. Belém: EDUFPA, 2008.

SOUZA, Kellcia Rezende; KERBAUY, Maria Teresa Miceli. Abordagem quanti-qualitativa: superação da dicotomia quantitativa-qualitativa na pesquisa em educação. Educação $e$ Filosofia. v. 31, n. 61, p. 21-44, jan./abr. 2017. Disponível em:

<http://www.seer.ufu.br/index.php/EducacaoFilosofia/article/view/29099/21313 >. Acesso em 18 jun. 2019.

\section{SOBRE OS AUTORES:}

\section{André Rodrigues Guimarães}

Doutor em Educação pela Universidade Federal do Pará (UFPA); Professor Adjunto IV da Universidade Federal do Amapá (UNIFAP), Brasil; Docente Permanente do Programa de PósGraduação em Educação da UNIFAP e do Programa de Pós-Graduação em Educação da UFPA. Líder do Grupo de Estudos e Pesquisas Marxismo, Trabalho e Políticas Educacionais (GEMTE/UNIFAP). E-mail: andre_unifap@yahoo.com.br

(iD http://orcid.org/0000-0003-1153-0771

\section{Cristiane de Sousa Brito}

Mestre em Educação pela Universidade Federal do Amapá (PPGED/UNIFAP); Professora da Educação Básica da rede privada de ensino, Brasil; Membro integrante do Grupo de Estudos e Pesquisas Marxismo, Trabalho e Políticas Educacionais (GEMTE/UNIFAP). E-mail: crisbrito56@live.com

iD http://orcid.org/0000-0002-3981-1949

\section{José Almir Brito dos Santos}

Doutorando em Educação na Universidade Federal do Pará (UFPA). Mestre em Educação pela Universidade Federal do Amapá (UNIFAP); Professor da Educação Básica da rede pública estadual no Amapá, Brasil. Membro integrante do Grupo de Estudos e Pesquisas Marxismo, Trabalho e Políticas Educacionais (GEMTE/UNIFAP).E-mail: prof.almir@ymail.com iD http://orcid.org/0000-0002-4252-1459 